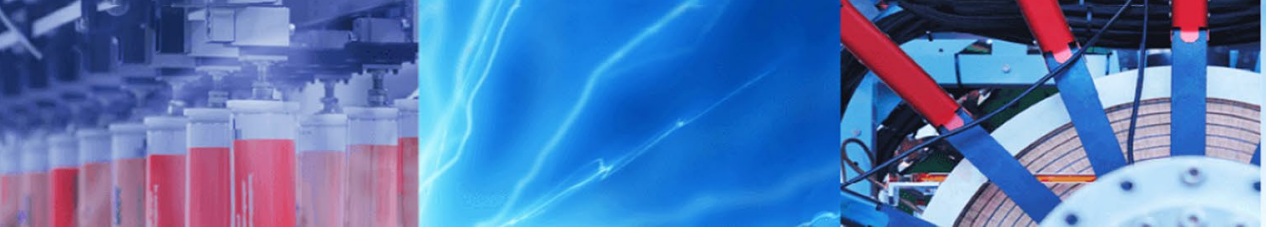

Research Article

\title{
Sorption of $\mathrm{As}(\mathrm{V})$ from aqueous solution using in situ growth $\mathrm{MgAl}-\mathrm{NO}_{3}$ layered double hydroxide thin film developed on AA6082
}

\author{
Muhammad Ahsan Iqbal $^{1}$ (D) $\cdot$ Humaira Asghar $^{2} \cdot$ Muhammad Adeel Iqbal $^{3} \cdot$ Michele Fedel $^{1}$
}

(c) Springer Nature Switzerland AG 2019

\begin{abstract}
In this work, the MgAl- $\mathrm{NO}_{3}$ layered double hydroxide (LDH) developed by the single-step in situ growth method is used as a robust sorbent to remove arsenic from aqueous solution. The MgAl-LDH exhibiting two different distinct morphologies (platelet structure and cauliflower-shaped structure) was developed on the AA6082 substrate with the variation in synthesis parameters, where AA6082 specimen acts as both the reactant and support. The structural characterizations were investigated through scanning electron microscopy, X-ray diffraction analysis, and energy dispersion spectroscopy, while the adsorption of arsenic on MgAl-LDH was studied through Langmuir and Freundlich models. The Langmuir isotherms have shown a maximum adsorption capacity of around 213 and $239 \mathrm{mg} / \mathrm{g}$ for platelet and cauliflower-like MgAl-LDH, respectively. The pseudo-first-order and pseudo-second-order Lagergren kinetic models were studied for the understanding of the adsorption kinetics. The results depicted that anion exchange and the electrostatic interaction are the possible reasons of arsenic sorption on MgAl-LDH, but the ion exchange mechanism is found to be the dominant mechanism. The maximum adsorption capacity of cauliflower-shaped MgAl-LDH was found to be slightly higher than platelet structure, but overall maximum arsenic adsorption uptake values of both in situ growth structures have found to be exceeded the mostly reported MgAl-LDH maximum adsorption capacities.
\end{abstract}

Keywords In situ growth MgAI-LDH ·AA6082 · Arsenic removal · Kinetics · Adsorption isotherm

\section{Introduction}

Arsenic contaminations in groundwater are considered a serious hazard for human health as well as for ecosystem due to their toxicity and carcinogenic nature [1]. According to the World Health Organization and the United States Environmental Protection Agency (USEPA) provided guideline, the maximum arsenic level should be less than $10 \mu \mathrm{g} / \mathrm{L}$ in the drinking water $[1,2]$. In that scenario, it is very alarming to found a much higher concentration of arsenic in drinking water in different regions throughout the world due to the presence of geological resources of arsenic in that areas and furthermore also due to anthropogenic pollution from different industrial processes. It is estimated that 150 million people in 70 different countries are at the risk of arsenic contaminations [3], while the rapid increase in industrial pollutants worldwide is causing more discharge of non-biodegradable heavy metals [4]. Therefore, it is indispensable to develop low-cost efficient water purification technologies to purify drinking water from heavy metals.

A number of approaches have been reported to remove arsenic, for instance, solvent extraction electrodialysis, membrane technologies, adsorption, coagulation, and ion exchange with certain limitations. Adsorption techniques among them are considered more promising due to their regeneration capability, design simplicity, operational easiness, and small-scale treatment plants applicability

$\triangle$ Muhammad Ahsan Iqbal, muhammadahsan.iqbal@unitn.it | 'Department of Industrial Engineering, University of Trento, via Sommarive 9, Povo, TN, Italy. ${ }^{2}$ US Pakistan Center for Advance Studies in Energy (USPCAS-E), National University of Science and Technology (NUST), Islamabad 44000, Pakistan. ${ }^{3}$ Department of Mechanical and Aerospace Engineering, Air University Islamabad, Islamabad, Pakistan. 
[5]. Recently, layered double hydroxide has got prominent attention as adsorbents due to their low cost, high anion exchange capability, greater surface area, nontoxic nature of composing elements, and also the availability of a wide range of cationic and anionic combinations [6-8]. Layered double hydroxide, a promising type of chemical conversion material, also known as hydrotalcite-like compounds or anionic clays, has got prominent attention in the fields of biomedical science, applied chemistry, coatings, and recently as environmental pollutants purifiers, to remove heavy metals from the water [9-11]. Generally, two different methods are employed to fabricate layered double hydroxide: single-step in situ approach $[8,12]$ and colloidal assembly technique $[13,14]$. This brucite-like structure contains positively charged layers being bonded together via charge-compensating anions and water molecules and thus acts as an organized structural material to facilitate effective charge transfer and also yields a comprehensive ion exchange area, which makes it enable for anion exchange with various active metal units [8]. The general process involved during LDH adsorption is electrostatic interaction, anion exchange, and physical adsorption [15, 16]. Among various types of developed layered double hydroxides, MgAl-LDH intercalated with $\mathrm{NO}_{3}^{-1}$ is known as effective adsorbents for the removal of $\mathrm{As}(\mathrm{V})$ from the aqueous solutions [17]. Although many studies have been done on the MgAl-LDH adsorptive properties [18-20], yet to the best of our knowledge, there has been no report on the in situ growth MgAl-LDH adsorptive behaviors for the arsenic removal and role of surface morphology on LDH ion exchange capabilities. We studied, in this work, two distinct LDH morphologies, i.e., platelet structure and cauliflower-shaped structure, to investigate arsenic adsorption behavior of in situ growth LDH.

In this contribution, MgAl-LDHs intercalated with nitrate anions were synthesized by the in situ growth method and their effectiveness on the arsenic adsorption behavior is investigated. The effectiveness of the arsenic removal is investigated by the adsorption isotherms and kinetics studies, while the structural characterization was investigated by XRD, SEM, and EDS analyses. The LDH film thickness, surface morphologies, and synthesis parameters have found to be an influential effect on the LDH adsorption process and their ion exchange capability.

\section{Experimental}

\subsection{Materials}

The AA6082 extruded bar was purchased from Meal Center (Italy), which mainly consists of magnesium (0.60-1.20\%), iron $(0.50 \%)$, silicon $(0.70-1.30 \%)$, copper $(0.10 \%)$, manganese $(0.40-1.00 \%)$, and of balance percentage of aluminum. The $\mathrm{Mg}\left(\mathrm{NO}_{3}\right)_{2} \cdot 6 \mathrm{H}_{2} \mathrm{O}$ (purity $\left.98 \%\right) \mathrm{NH}_{4} \mathrm{NO}_{3}$ (purity $95 \%$ ), and $\mathrm{NaOH}$ (purity $\geq 98 \%$ ) were purchased from SigmaAldrich Corporation.

\subsection{Synthesis of MgAl-layered double hydroxide film}

The in situ growth layered double hydroxide film is developed on the AA6082 substrate $\left(3.14 \mathrm{~cm}^{2}\right)$, based on our previous work [8]. The specimens were initially ground with silicon carbon paper, started from 500-grit paper to 1000-, 2400-, and 4000-grit paper, respectively. The samples were cleaned with the deionized water and further with pure ethanol ultrasonically for $15 \mathrm{~min}$. Lastly, the specimens were immersed in $0.1 \mathrm{M}$ aqueous $\mathrm{NaOH}$ solution for $1 \mathrm{~min}$ to etch the oxide layer on the surface of the alloy. From our previous study [8], we selected two different synthesis conditions to develop distinct MgAl-LDH morphologies, i.e., cauliflower-like and platelet-shaped structure. The following combinations were used for that purpose: $0.008 \mathrm{MgNO}_{3} \& 0.048 \mathrm{NH}_{4} \mathrm{NO}_{3}$ and $0.028 \mathrm{MgNO}_{3}$ $\& 0.084 \mathrm{NH}_{4} \mathrm{NO}_{3}$ at $60^{\circ} \mathrm{C}$ and $80^{\circ} \mathrm{C}$, respectively, at a $\mathrm{pH}$ of 10 for $24 \mathrm{~h}$ of crystallization time. After that, the developed coated specimens were dried at room temperature.

\section{Characterization}

The structural characterization of MgAl-LDH film is carried out by the SEM (JEOL-IT300 microscope equipped with an EDS detector), while XRD patterns of the calcined and uncalcined LDH-coated samples were recorded by X-ray diffraction (XRD) (X'Pert HighScore diffractometer, Rigaku, Japan) by using cobalt K-a $\left(\lambda=1.789 \AA^{-1}\right)$ emission source at $10 \mathrm{~mA}$ and $30 \mathrm{kV}$ conditions.

The arsenic concentrations in the solution were determined by the atomic absorption spectrophotometer [AAS vario 6, Analytic Jena (Germany)]. To investigate the adsorption behavior, MgAl-LDH specimens were dipped in $20 \mathrm{~mL}$ model solutions of various arsenic concentrations (0.01-0.1 M) for $24 \mathrm{~h}$. To determine adsorption kinetics, $0.1 \mathrm{M}$ arsenic solution $(500 \mathrm{~mL}$ ) was used to investigate adsorption behavior as a function time at room temperature. The Lagergren pseudo-first-order and pseudo-second-order fitting models were employed to understand the mechanism of $\mathrm{As}(\mathrm{V})$ sorption on MgAl-LDHs.

\section{Results and Discussion}

Figure 1 shows the XRD patterns of MgAl-LDHs before and after the $\mathrm{As}(\mathrm{V})$ adsorption. It can be seen that as-prepared as well as treated specimens have shown the characteristic 
peaks of layered double hydroxide structure, as described in the literature [21]. The characteristic peaks of (003), (006), (009) crystal planes are attributed to the presence of $\mathrm{MgAl}-\mathrm{NO}_{3} \mathrm{LDH}$ structure. The sharp and symmetric characteristic peaks demonstrated well-crystalline and ordered structure of MgAl-LDH. The LDH structural peaks after $\mathrm{As}(\mathrm{V})$ adsorption have shown the similar original LDH characteristic peaks, which describe the intactness of layered double hydroxide structure which was further confirmed by the SEM analysis. The intense reflection peaks of (003) at low $2 \theta$ value exhibited the interlayer distance $\left(d_{003}\right)$ of $\approx 0.90 \mathrm{~nm}$ and $\approx 0.89 \mathrm{~nm}$ for cauliflower and platelet LDH structure, respectively. The comparatively high interlayer thickness of cauliflower LDH structure may be attributed to strong $\mathrm{NO}_{3}^{-1}$ intercalation inside the galleries of brucite-like structure. However, due to the formation of carbonate anions, a small absorption peak of $d_{003}$ for MgAlLDH platelet structure can also be observed. The intensity and broadness of the reflection peaks vary after the $\mathrm{As}(\mathrm{V})$ intercalations, which indicates the anion exchange interaction between $\mathrm{As}(\mathrm{V})$ in the solution and nitrates in the LDH galleries. After the anion exchange, the $d_{003}$ value decreased, possibly due to the new orientation of $\mathrm{As}(\mathrm{V})$ inside the layers, the water molecules reorientation during the anion exchange process, and also due to the $\mathrm{HAsO}_{4}^{-2}$ ionic radius; moreover, reduced interlayer distance described the strong electrostatic interaction between the positive layers and the intercalated anions [22]. As revealed from the SEM observations (Figs. 2 and 3), compact and uniform interviewed LDH structures were obtained, which

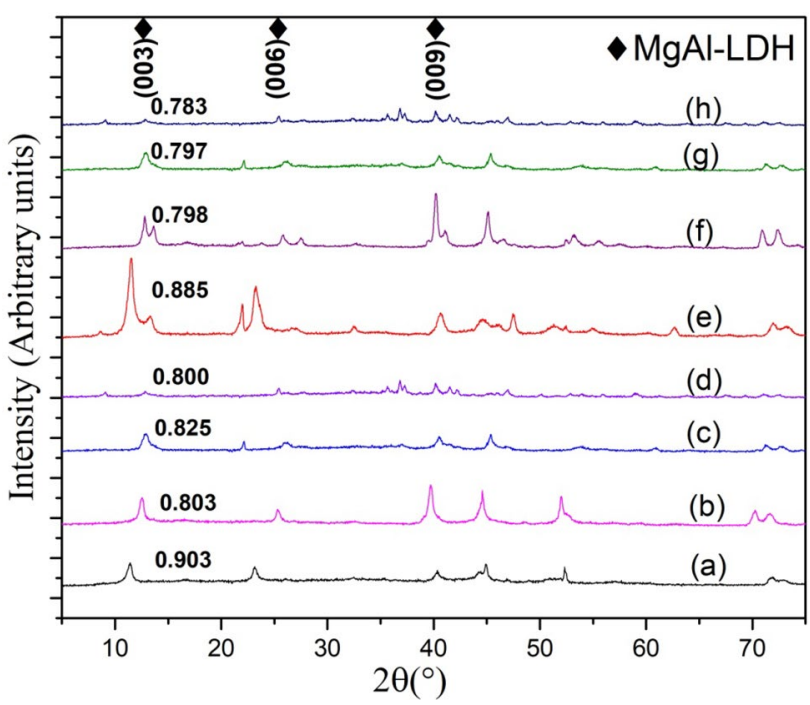

Fig. 1 XRD patterns of cauliflower and platelet MgAl-LDH before and after treatment with different sodium arsenate concentrated solutions. (a) Cauliflower MgAl-LDH as prepared, (b) $0.06 \mathrm{M}$, (c) $0.08 \mathrm{M}$, (d) $0.1 \mathrm{M}$, (e) platelet MgAl-LDH as prepared, (f) $0.06 \mathrm{M}$, (g) $0.08 \mathrm{M}$, (h) $0.1 \mathrm{M}$. (Interlayer distance $\left(d_{003}\right)$ is listed with each peak) retained almost their original shape after the adsorption, but there can also be seen a few aggregations of particles on the MgAl-LDH surface. So we can assume that during the adsorption, two possible interactions took place: (1) physical interaction of $\mathrm{LDH}$ surface with the $\mathrm{As}(\mathrm{V})$ and $(2)$ anion exchange process between the nitrates and $A s(\mathrm{~V})$. Figure 4 shows the EDS findings after treatment of MgAl$\mathrm{LDH}$ with a $0.1 \mathrm{M}$ arsenic solution, and it is clear that after treatment MgAl-LDH structure mainly contains $\mathrm{Mg}, \mathrm{Al}, \mathrm{As}$, and oxygen, while the small amount of carbon was also evident in EDS study, caused by the contaminations, which results in the formation of carbonate anions.

The arsenic adsorption isotherms (adsorption capacity) were measured by varying the initial arsenic concentrations in the model solution for a contact period of $24 \mathrm{~h}$, as shown in Fig. 5. The amount of adsorption is found to increase with the increase in arsenic concentration in the solution (from 0.02 to $0.1 \mathrm{M}$ ) at a pH of 7 . It is also interesting to note that cauliflower-like LDH structure has shown the highest arsenic adsorption value $(239 \mathrm{mg} / \mathrm{g}$ ) compared to that of platelet structure $(206 \mathrm{mg} / \mathrm{g})$, possibly due to its high film thickness and of greater contoured nanosheets which relatively increase its surface area. But overall, both structures have effectively removed the arsenate from the water. The equilibrium arsenic adsorption amount is calculated by Eq. (1) [23]:

$q=\frac{V\left(C_{o}-C_{t}\right)}{m}$

where " $V$ " is the volume of the solution in $L, C_{o}$ is the initial arsenic concentration, while $C_{t}$ is the concentration at time $t$ in $\mathrm{mg} / \mathrm{L}$. $\mathrm{q}(\mathrm{mg} / \mathrm{g})$ is the amount of arsenic sorbed $(\mathrm{mg} / \mathrm{g})$ at a time " $t$ " on MgAl-LDH, and " $m$ " is the sorbent mass (MgAl-LDH film) in grams calculated by the mass difference of before and after MgAl-LDH formation on AA6082 substrate. (The specimens were dried at $60^{\circ} \mathrm{C}$ for $40 \mathrm{~min}$ before mass measurement.) Figure 5 shows the graphical relationship between $q_{e}$ and $C_{e^{\prime}}$ and it is clear that the adsorption capacity of MgAl-LDH structure increases with the increase in amount of $A s(V)$ in the model solution, because of larger concentration gradient which causes an increase in mass transfer driving force and leads to the availability of more arsenate molecules on the MgAl-LDH active sites.

Further, the results of adsorption experiments were fitted by using the Langmuir model and Freundlich model to analyze the adsorption behavior of arsenate on MgAl$\mathrm{LDH}$. The general assumption of the Langmuir model is the uniform adsorption process with the context that each adsorption surface consisted of identical binding sites with 


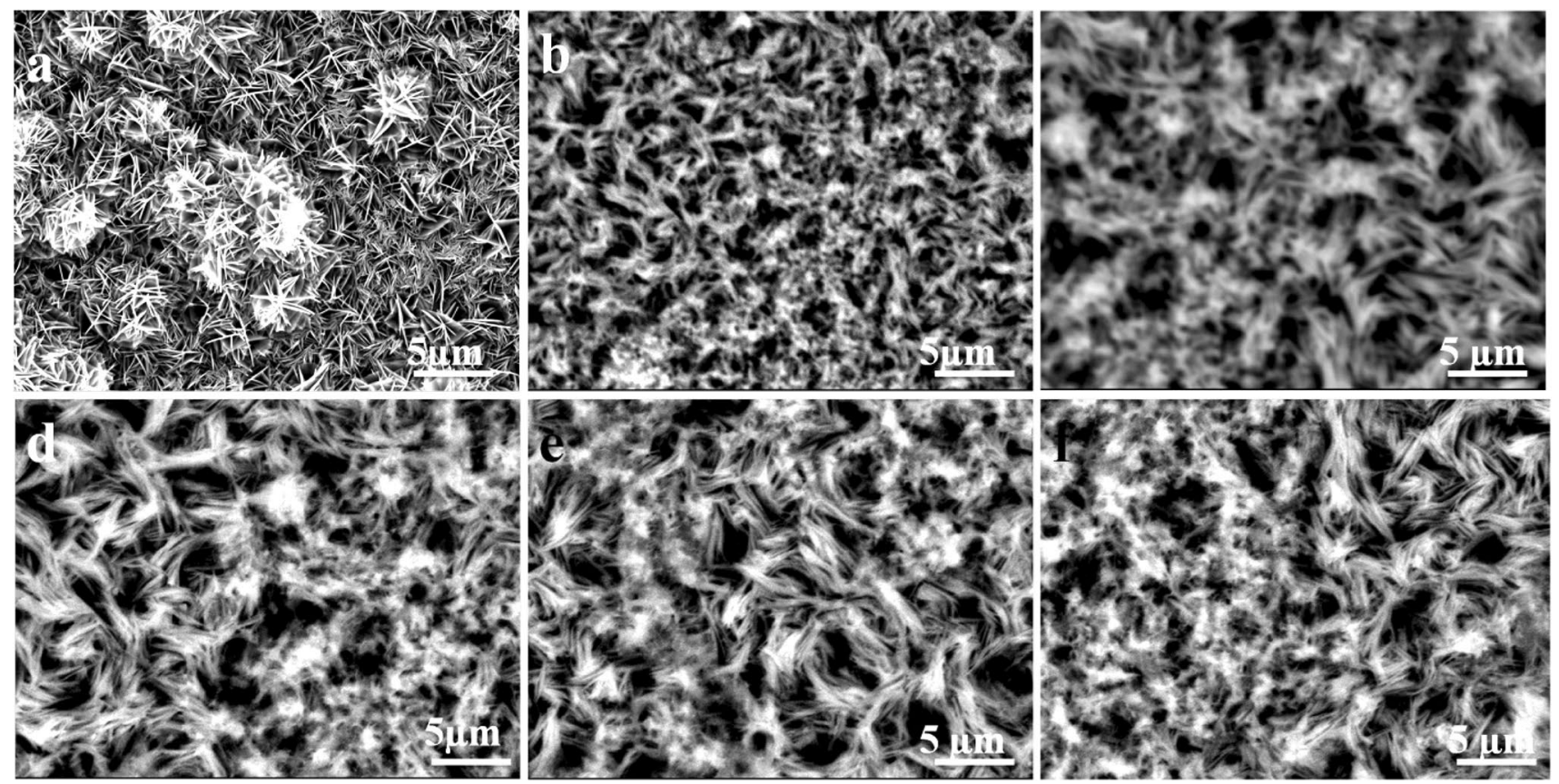

Fig. 2 SEM images of platelet MgAl-LDH film with adsorption in different $\left(\mathrm{Na}_{3} \mathrm{AsO}_{4}\right)$ concentration solutions for $24 \mathrm{~h}$, a as-prepared $\mathrm{LDH}$, b $0.02 \mathrm{M}, \mathbf{c} 0.04 \mathrm{M}, \mathbf{d} 0.06 \mathrm{M}$, e $0.08 \mathrm{M}, \mathbf{f} 0.1 \mathrm{M}$
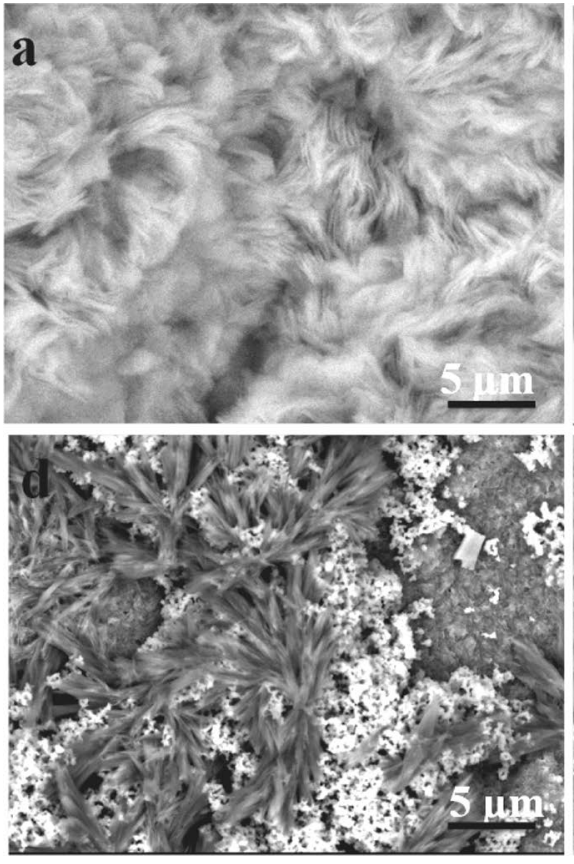
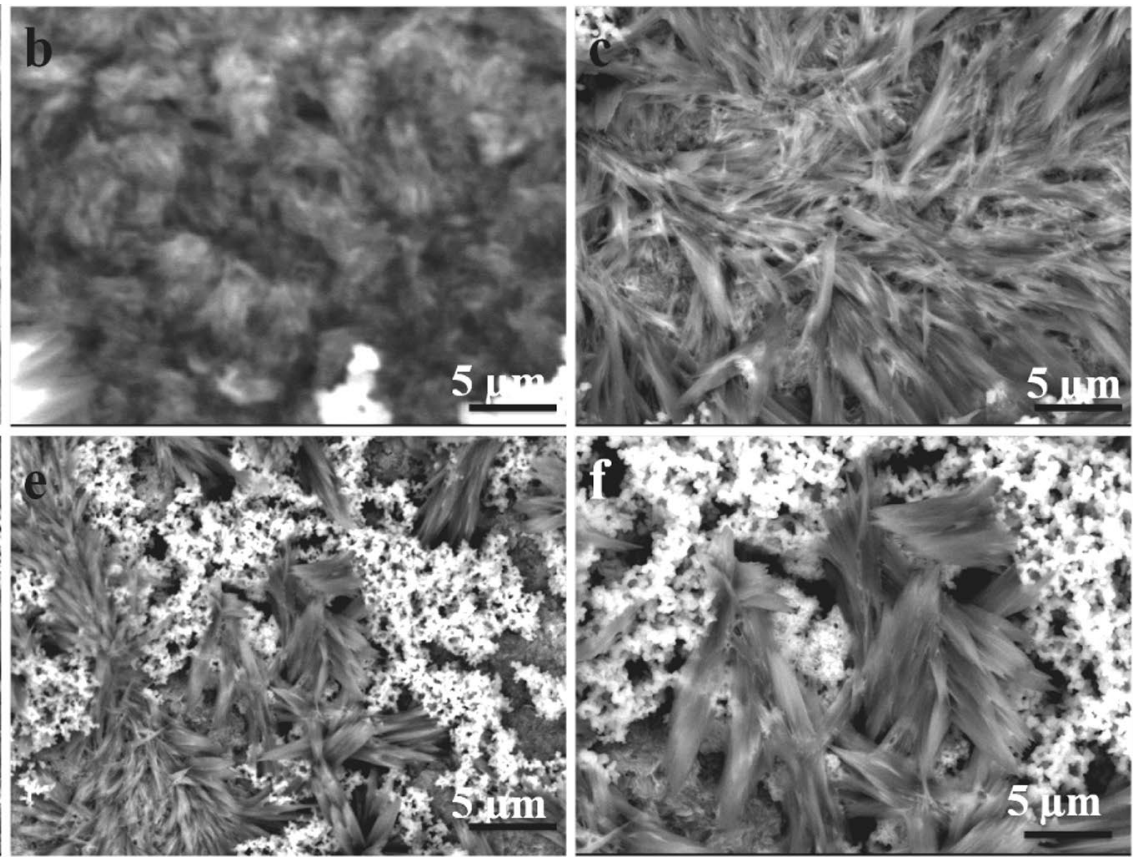

Fig. $3 \mathrm{SEM}$ images of cauliflower MgAl-LDH film with adsorption in different $\left(\mathrm{Na}_{3} \mathrm{AsO}_{4}\right)$ concentration solutions for $24 \mathrm{~h}$, a as-prepared $\mathrm{LDH}$, b $0.02 \mathrm{M}$, c $0.04 \mathrm{M}$, d $0.06 \mathrm{M}$, e $0.08 \mathrm{M}$, f $0.1 \mathrm{M}$

monolayer adsorption behavior. The linear form of the Langmuir model can be written as follows:

$\frac{C_{e}}{q_{e}}=\frac{1}{b \times Q_{0}}+\frac{C_{e}}{Q_{0}}$ where $C_{e} / q_{e}(\mathrm{mg} / \mathrm{g})$ is the equilibrium ratio between the concentration of adsorbate ions and the number of adsorbate ions adsorbed on per unit weight of MgAI-LDH, $Q_{0}$ is associated with the maximum adsorption capacity, while " $b$ " is termed as Langmuir constant. If $C_{e} / q_{e}$ is plotted

SN Applied Sciences 


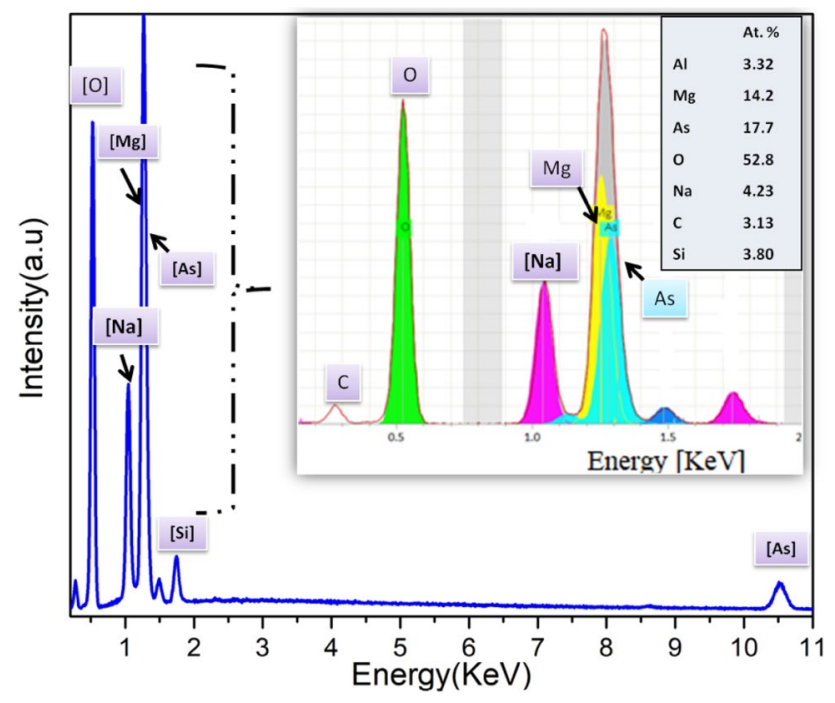

Fig. 4 EDS spectrum of MgAl-LDH (cauliflower) after treatment with $0.1 \mathrm{M}$ sodium arsenate concentrated solution

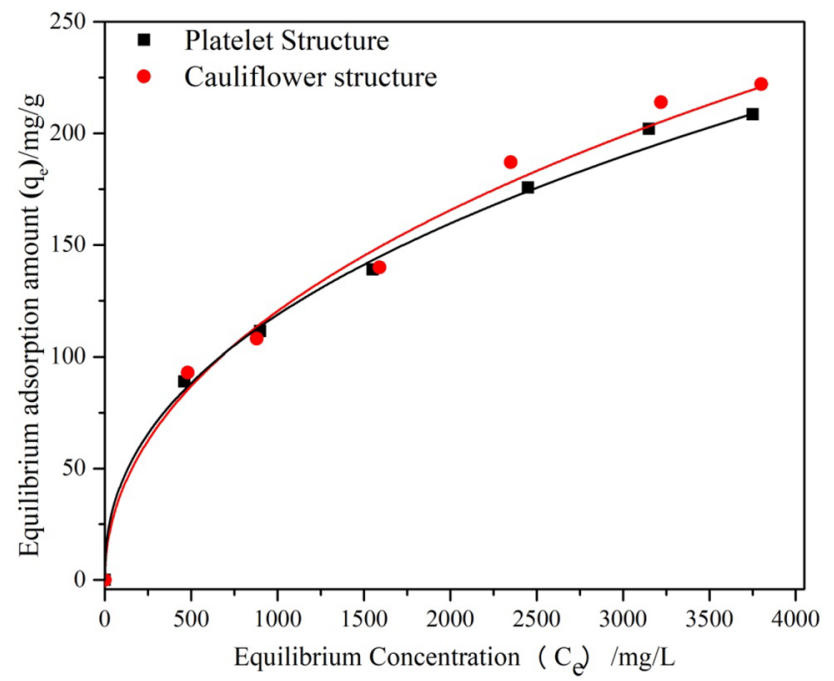

Fig. 5 Equilibrium adsorption isotherms of MgAl-LDHs by varying the initial $\mathrm{As}(\mathrm{V})$ concentration in the arsenic solution

against $C_{e}$, then from the slope and intercept of this plot, $Q_{0}$ and $b$ can be determined, respectively (Fig. 6).

On the other hand, Freundlich model is another empirical description of non-ideal adsorption on the heterogeneous surface and provided an idea about the multilayer sorption with the description that the binding surface energy reduces with the increase in solute adsorbed on the surface. The Freundlich model is expressed as:

$\log q_{e}=\log k+\frac{1}{n} \log C_{e}$

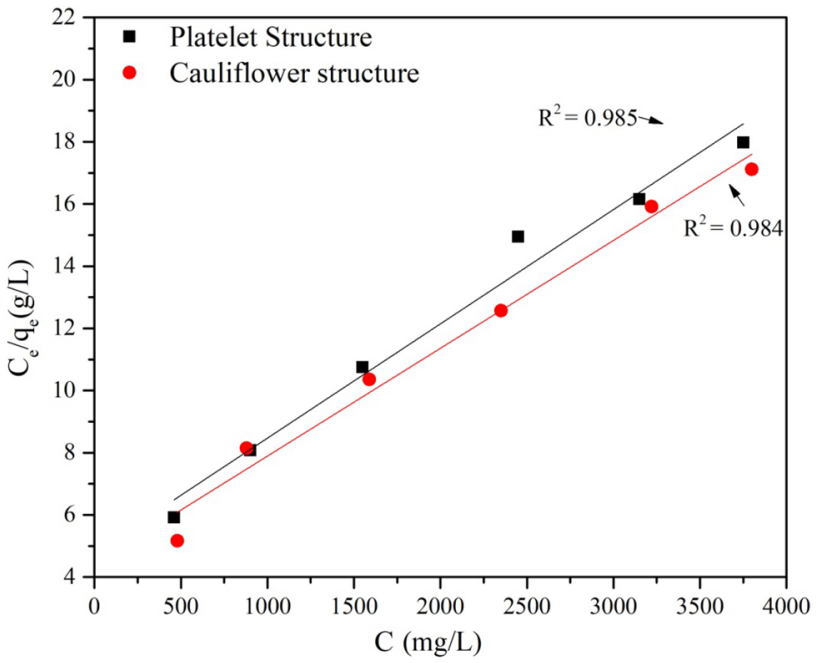

Fig. 6 A highly linear Langmuir adsorption isotherm of $\mathrm{As}(\mathrm{V})$ by MgAl-LDHs

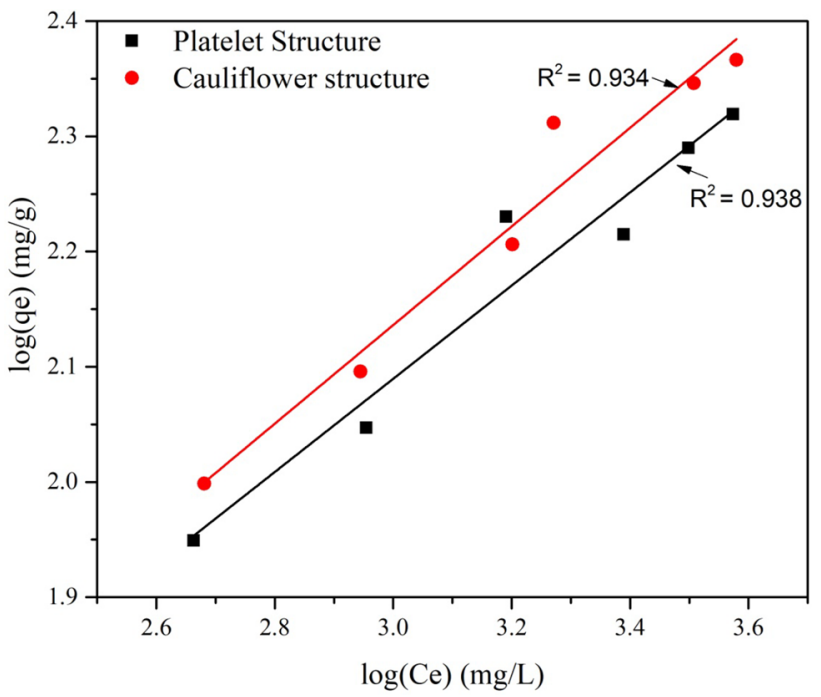

Fig. 7 Freundlich isotherm of $\mathrm{As}(\mathrm{V})$ by $\mathrm{MgAl}-\mathrm{LDH} s$

By plotting $\log q_{e}$ versus $\log C_{e}$, the coefficients " $k$ " and " $n$ " can be determined if a straight line is obtained. Freundlich isotherms for $\mathrm{As}(\mathrm{V})$ adsorption on $\mathrm{MgAl}-\mathrm{NO}_{3} \mathrm{LDHs}$ are shown in Fig. 7. The correlation coefficient values and isotherm constants of Langmuir and Freundlich isotherms are listed in Table 1.

From the obtained fitting results, it can be seen that the maximum adsorption capacity of $\mathrm{As}(\mathrm{V})$ was found by the Langmuir model with high linearity (Table 1 ). The maximum adsorption capacities of cauliflower and platelet structure for Langmuir $\mathrm{As}(\mathrm{V})$ adsorption isotherms are found to be 239 and $212 \mathrm{mg} / \mathrm{g}$, respectively. The results obtained by the Langmuir model are also in 
Table 1 Langmuir and Freundlich parameters for As(V) removal by MgAl-LDHs

\begin{tabular}{|c|c|c|c|c|}
\hline \multirow[t]{2}{*}{ LDH structure } & \multicolumn{4}{|c|}{ Langmuir model } \\
\hline & $\overline{R^{2}}$ & $Q_{o}(\mathrm{mg} / \mathrm{g})$ & (L/mg) & Slope \\
\hline Platelet & 0.985 & 212.8 & 0.0010 & 0.0047 \\
\hline Cauliflower & 0.984 & 238.1 & 0.0008 & 0.0042 \\
\hline \multirow[t]{2}{*}{ LDH structure } & \multicolumn{4}{|c|}{ Freundlich model } \\
\hline & $\overline{R^{2}}$ & $K$ & $1 / n$ & Slope \\
\hline Cauliflower & 0.994 & 6.622165 & 0.42 & 0.416 \\
\hline Platelet & 0.998 & 7.063176 & 0.42 & 0.421 \\
\hline
\end{tabular}

Table 2 A comparison study with other reports to adsorb $\mathrm{As}(\mathrm{V})$ by $\mathrm{MgAl}-\mathrm{LDHs}$

\begin{tabular}{|c|c|c|c|}
\hline \multirow[t]{2}{*}{ Layered double hydroxide (adsorbents) } & \multirow[t]{2}{*}{ Synthesis method } & \multicolumn{2}{|c|}{ Adsorption capacity $(\mathrm{mg} / \mathrm{g})$} \\
\hline & & $\mathrm{As}(\mathrm{V})$ & References \\
\hline $\mathrm{MgAl}-\mathrm{NO}_{3}-\mathrm{LDH}$ (cauliflower structure) & In situ & 239 & This work \\
\hline $\mathrm{MgAl}-\mathrm{NO}_{3}-\mathrm{LDH}$ (platelet structure) & In situ & 212 & This work \\
\hline $\mathrm{MgAINO}_{3}-\mathrm{LDH}$ & Co-precipitation & 143 & Rahman et al. [18] \\
\hline $\mathrm{MgAINO}_{3}-\mathrm{LDH}$ & Co-precipitation & 77 & Rahman et al. [18]. \\
\hline $\mathrm{MgAlNO}_{3}-\mathrm{LDH}$ & Co-precipitation & 100 & Doušová et al. [24] \\
\hline $\mathrm{MgAlCO}_{3}-\mathrm{LDH}$ & Co-precipitation & 45 & Wu et al. [25] \\
\hline MgAICl-LDH & Co-precipitation & 88 & Wu et al. [25] \\
\hline $\mathrm{MgAINO}_{3}-\mathrm{LDH}$ (calcined) & Co-precipitation & 216 & Yu et al. [26] \\
\hline $\mathrm{MgAlCO}_{3}-\mathrm{LDH}$ & Co-precipitation & 121 & Huang et al. [20] \\
\hline
\end{tabular}

close agreement with the results obtained by Eq. (1). So we can say that the cauliflower-like MgAI-LDH structure has shown slightly better performance than the plateletlike structure. The results obtained here are also relatively higher than the MgAl-LDH synthesized by co-precipitation method, from the literature studies (Table 2) [18, 20, 24-26].

\section{Kinetics of $A s(V)$ removal}

Figures 8 and 9 show the adsorption of arsenate by $\mathrm{MgAl}-\mathrm{NO}_{3} \mathrm{LDHs}$ as a function of time to understand the kinetics of $\mathrm{As}(\mathrm{V})$ removal. With the passage of time, $\mathrm{As}(\mathrm{V})$ concentration decreases in the solution which caused the decline in mass transfer due to lowering of static driving forces. Therefore, we can say that the adsorption is rapid initially at the start of the process when there was a high gradient of concentration and then it decreased with the passage of time until the system approaches the equilibrium. For the kinetics modeling and understanding of the mechanism of arsenate adsorption, Lagergren pseudofirst-order and pseudo-second-order models were studied. Lagergren equation is used [(Eq. (4)] to understand the adsorption kinetics, and in the case of a pseudo-first-order process, the Lagergren equation after integration with

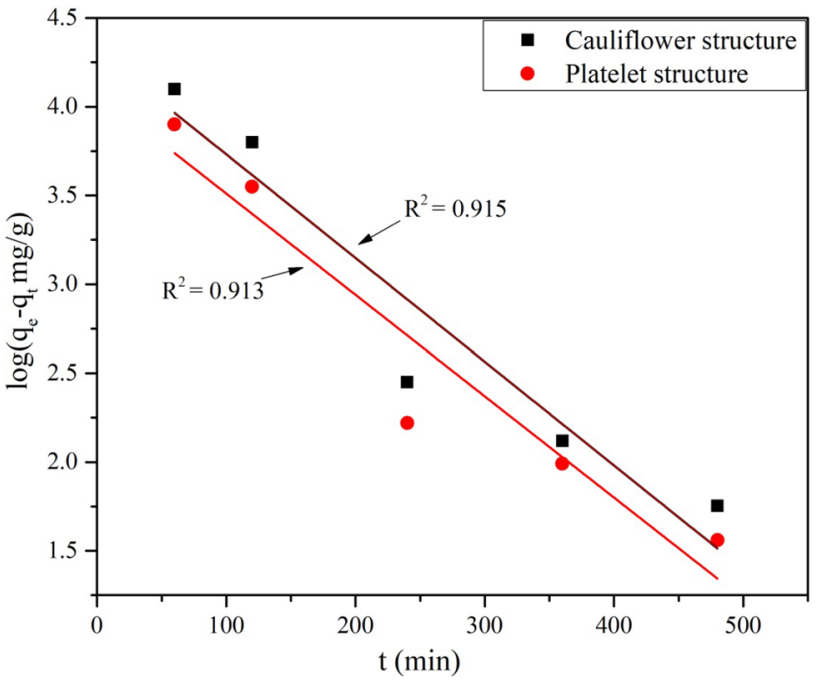

Fig. 8 Pseudo-first-order model for As(V) removal by MgAl-LDHs

the conditions $\left(q_{t}=0\right.$ at $t=0, q_{t}=q_{t}$ at $\left.t=t\right)$ is expressed in Eq. (5), where $q_{t}$ is the amount of arsenate adsorbed in $\mathrm{mg} / \mathrm{g}$ at time $t, k_{1}$ is the time constant $\left(\mathrm{min}^{-1}\right)$, and $q_{e}$ is the equilibrium adsorption value in $\mathrm{mg} / \mathrm{g}$ at time $t$ (calculated by the extrapolation of the experimental data). Equation 6 expresses the pseudo-second-order Lagergren equation, where $k_{2}$ is the second-order rate constant in $\mathrm{g} / \mathrm{mg} \times \mathrm{min}$. 


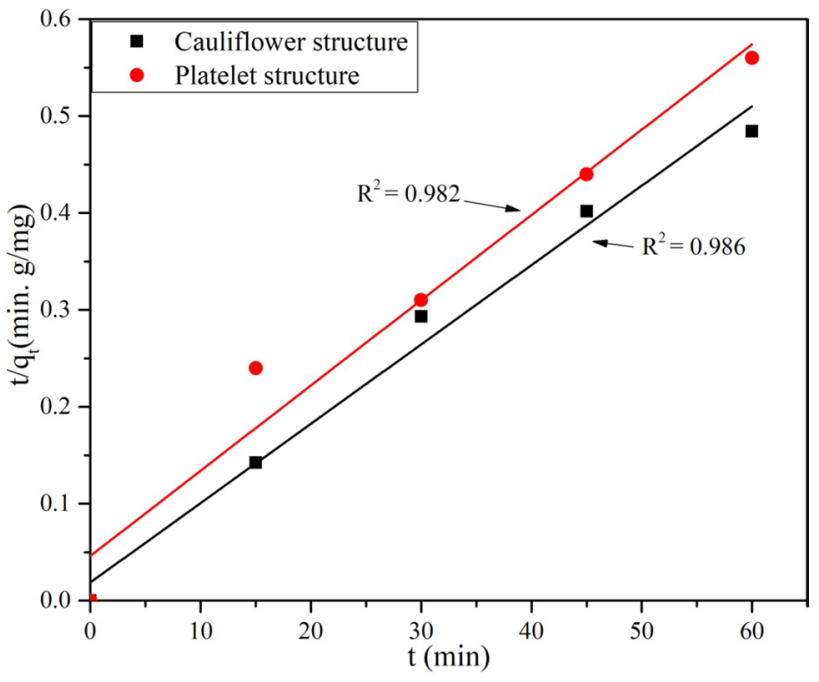

Fig. 9 Pseudo-second-order model for $\mathrm{As}(\mathrm{V})$ removal by $\mathrm{MgAl}-$ LDHs

The pseudo-first-order kinetic model provides a general idea about the rate of change in arsenate concentration with the passage of time and stated that the change in the concentration of the adsorbate and the amount of adsorbent over time is logarithmically proportional [27], while a pseudo-second-order kinetic model suggests that the number of active sites occupied on the adsorbent is directly proportional to the adsorption capacity. The pseudo-first-order [28] [Eq. (5)] and pseudo-second-order [Eq. (6)] [29] equations are described as:

$\frac{d q_{t}}{d_{t}}=k_{1}\left(q_{e}-q_{t}\right)$

$\ln \left(q_{e}-q_{t}\right)=\ln \left(q_{e}\right)-k_{1} t$

$\frac{1}{q_{t}}=\frac{1}{k_{2}\left(q_{e}^{2}\right)}+\frac{t}{q_{e}}$

The correlation coefficients ( $R^{2}$ values), rate constants, and other parameters for these two kinetic models were calculated from the respective slope and intercept and are tabulated in Table 3. The pseudo-first-order model shows a lower correlation (low linearity) than the pseudo-second-order model, which indicates the pseudo-second-order model is a better approach for the As $(\mathrm{V})$ removal kinetics. Due to the second-order reaction kinetics, we can say that the ion exchange of nitrate with $\mathrm{As}(\mathrm{V})$ is the rate-determining step [30]. Therefore, we can conclude about the $\mathrm{As}(\mathrm{V})$ mechanism that the reaction rate of arsenate adsorption mainly depends on the anion exchange process between nitrate ions and $\mathrm{As}(\mathrm{V})$ and also that the rate of reaction depends upon the concentrations of $\mathrm{NO}_{3}^{-1}$ ions bound to the $\mathrm{MgAl}-\mathrm{NO}_{3}-\mathrm{LDH}$ and $\mathrm{As}(\mathrm{V})$ ions in the model solution. It can also be concluded that the anion exchange process effectively takes place between the $\mathrm{NO}_{3}$ and $\mathrm{HAsO}_{4}^{-2}$, due to the relatively higher charge density of $\mathrm{HAsO}_{4}^{-2}$ ions. The SEM and XRD analyses already confirmed that the basic LDH structure remains almost intact, which is aligned with the above description of the mechanism.

Figure 10 shows the as-prepared MgAl-LDH film thickness along with respective EDS analysis in at.\% in-plane

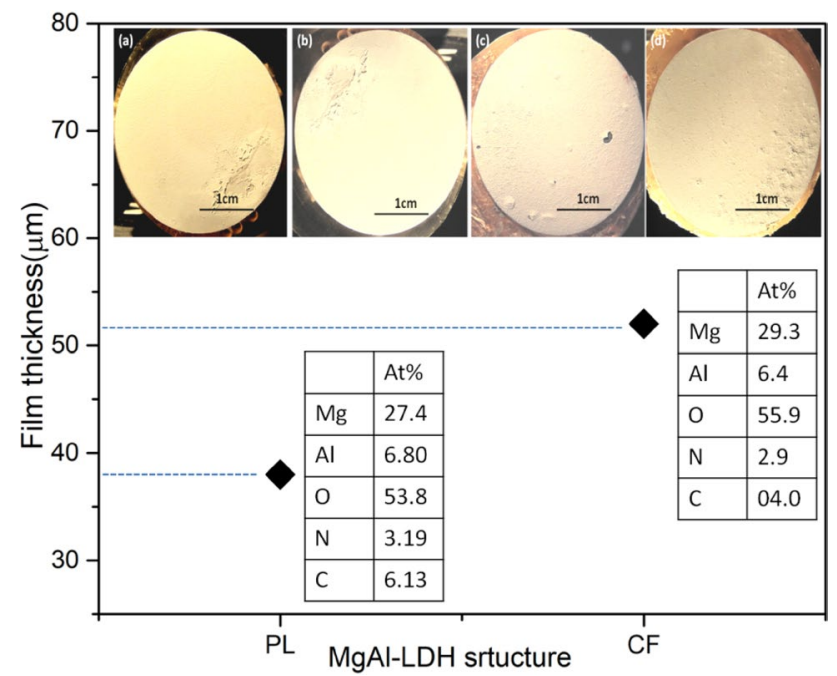

Fig. $10 \mathrm{MgAl}-\mathrm{LDH}$ thickness of the as-prepared films; $P L$ platelet structure, CF cauliflower structure along with EDS atomic percentage, insight is the specimen surfaces after treatment with sodium arsenate for $24 \mathrm{~h}$, platelet structure (a) $0.08 \mathrm{M}$, (b) $0.1 \mathrm{M}$, cauliflower-like structure, (c) $0.08 \mathrm{M}$, (d) $0.1 \mathrm{M}$
Table 3 Kinetic parameters for $\mathrm{As}(\mathrm{V})$ removal by MgAl-LDHs

\begin{tabular}{llllll}
\hline Kinetic model & LDH morphology & $Q_{\mathrm{e}}(\mathrm{mg} / \mathrm{g})$ & $R^{2}$ & $K_{1}$ & Slope \\
\hline Pseudo-first-order & Platelet & 99.86194 & 0.913 & 0.0057 & 0.0057 \\
& Cauliflower & 102.3293 & 0.915 & 0.0058 & 0.0058 \\
& LDH morphology & $Q_{2}(\mathrm{mg} / \mathrm{g})$ & $R^{2}$ & $K_{2}$ & Slope \\
Pseudo-second-order & Platelet & 113.6364 & 0.986 & 0.004188 & 0.0088 \\
& Cauliflower & 122.1001 & 0.982 & 0.001454 & 0.0082 \\
\hline
\end{tabular}


scanning mode, while the thickness is around $38 \pm 0.98$ and $52 \pm 1.06 \mu \mathrm{m}$ for platelet and cauliflower-like structure, respectively, measured by the cross-sectional analysis of the film. Figure 10 (insets) shows the MgAl-LDH surface, just for representation, and after treatment with $0.1 \mathrm{M}$ sodium arsenate solution for $24 \mathrm{~h}$, the MgAl-LDH film has sustained the initial structure and no dissolution was observed on contact with the arsenic solution.

\section{Conclusion}

From the obtained findings in this study, it can be concluded that surface morphologies of MgAl-LDH have an influential effect on the arsenic adsorption capacity, and here, cauliflower-like structure has shown slightly better adsorption capacity $(238 \mathrm{mg} / \mathrm{g}$ ) compared to the platelet structure $(212 \mathrm{mg} / \mathrm{g})$. The results also showed that the Langmuir model has shown the better fitting of the adsorption capacity, while the Lagergren pseudosecond-order equation better translates the kinetics of arsenic adsorption. From the results, it is clear that arsenic adsorption occurs due to (1) surface adsorption and (2) by the anion exchange of $\mathrm{NO}_{3}^{-1}$ ions with the $\mathrm{As}(\mathrm{V})$, but the anion exchange process of $\mathrm{NO}_{3}$ and $\mathrm{As}(\mathrm{V})$ is the main arsenic adsorption process. The in situ growth $\mathrm{MgAINO}_{3}-\mathrm{LDH}$ adsorption capacity of arsenate was found to be higher as compared to the $\mathrm{MgAINO}_{3}$ - $\mathrm{LDH}$ developed by the coprecipitation method (literature study), possibly due to the higher film thickness, high surface area, and layer-by-layer uniform structural geometry of in situ growth MgAI-LDH. This work could be useful also as a baseline for the possible utilization of such systems as a coating material for the removal of arsenic.

\section{Compliance with ethical standards}

Conflicts of interest The authors declare no conflict of interest.

\section{References}

1. WHO (2011) Edition, Fourth. “Guidelines for drinking-water quality". WHO Chron 38(4):104-108

2. World Health Organization (2004) Guidelines for drinking-water quality: recommendations, vol 1. World Health Organization, Geneva

3. Ravenscroft $P$ (2007) Predicting the global distribution of arsenic pollution in groundwater. In: Royal Geographical Society annual international conference, Department of Geography, Cambridge University, 29 Aug, vol 1. http://phys4.harvard.edu/ wilson/ arsenic/conferences
4. He F, Lu Z, Song M, Liu X, Tang H, Huo P, Fan W, Dong H, Wu $X$, Xing $G$ (2019) Construction of ion imprinted layer modified $\mathrm{ZnFe}_{2} \mathrm{O}_{4}$ for selective $\mathrm{Cr}(\mathrm{VI})$ reduction with simultaneous organic pollutants degradation based on different reaction channels. Appl Surf Sci. https://doi.org/10.1016/j.apsus c.2019.03.311

5. Shan RR, Yan LG, Yang K, Hao YF, Du B (2015) Adsorption of Cd (II) by $\mathrm{Mg}-\mathrm{Al}-\mathrm{CO}_{3}$-and magnetic $\mathrm{Fe}_{3} \mathrm{O}_{4} / \mathrm{Mg}-\mathrm{Al}-\mathrm{CO}_{3}$-layered double hydroxides: kinetic, isothermal, thermodynamic and mechanistic studies. J Hazard Mater 299:42-49

6. Iqbal M, Fedel M (2019) Effect of synthesis conditions on the controlled growth of MgAl-LDH corrosion resistance film: structure and corrosion resistance properties. Coatings 9(1):30

7. Carretero MI (2002) Clay minerals and their beneficial effects upon human health. A review. Appl Clay Sci 21(3-4):155-163

8. Iqbal MA, Fedel M (2018) The effect of the surface morphologies on the corrosion resistance of in situ growth MgAl-LDH based conversion film on AA6082. Surf Coat Technol 352:166-174

9. Leroux F, Taviot-Guého C (2005) Fine tuning between organic and inorganic host structure: new trends in layered double hydroxide hybrid assemblies. J Mater Chem 15(35-36):3628-3642

10. Evans DG, Duan X (2006) Preparation of layered double hydroxides and their applications as additives in polymers, as precursors to magnetic materials and in biology and medicine. Chem Commun 5:485-496

11. Wu X, Tan X, Yang S, Wen T, Guo H, Wang X, Xu A (2013) Coexistence of adsorption and coagulation processes of both arsenate and NOM from contaminated groundwater by nanocrystallined Mg/Al layered double hydroxides. Water Res 47(12):4159-4168

12. Iqbal MA, Fedel $M$ (forthcoming) Effect of operating parameters on the structural growth of ZnAl layered double hydroxide on AA6082 and corresponding corrosion resistance properties. J Coat Technol Res. https://doi.org/10.1007/s11998-019-00227-0

13. Chen $\mathrm{H}$, Zhang F, Fu S, Duan X (2006) In situ microstructure control of oriented layered double hydroxide monolayer films with curved hexagonal crystals as superhydrophobic materials. Adv Mater 18(23):3089-3093

14. Wang L, Li C, Liu M, Evans DG, Duan X (2007) Large continuous, transparent and oriented self-supporting films of layered double hydroxides with tunable chemical composition. Chem Commun 2:123-125

15. Gong J, Liu T, Wang X, Hu X, Zhang L (2011) Efficient removal of heavy metal ions from aqueous systems with the assembly of anisotropic layered double hydroxide nanocrystals@ carbon nanosphere. Environ Sci Technol 45(14):6181-6187

16. Zhang $H$, Huang $F$, Liu DL, Shi $P(2015)$ Highly efficient removal of $\mathrm{Cr}(\mathrm{VI})$ from wastewater via adsorption with novel magnetic $\mathrm{Fe}_{3} \mathrm{O}_{4} @ \mathrm{C} @ \mathrm{MgAl}$-layered double-hydroxide. Chin Chem Lett 26(9):1137-1143

17. Goh KH, Lim TT, Dong Z (2009) Enhanced arsenic removal by hydrothermally treated nanocrystalline Mg/Al layered double hydroxide with nitrate intercalation. Environ Sci Technol 43(7):2537-2543

18. Rahman MT, Kameda T, Kumagai S, Yoshioka T (2017) Adsorption isotherms and kinetics of arsenic removal from aqueous solution by $\mathrm{Mg}-\mathrm{Al}$ layered double hydroxide intercalated with nitrate ions. Reaction Kinet Mech Catal 120(2):703-714

19. Kovačević D, Njegić Džakula B, Hasenay D, Nemet I, Rončević S, Dékány l, Petridis D (2013) Adsorption of arsenic on MgAl layered double hydroxide. Croat Chem Acta 86(3):273-279

20. Huang PP, Cao CY, Wei F, Sun YB, Song WG (2015) MgAl layered double hydroxides with chloride and carbonate ions as interlayer anions for removal of arsenic and fluoride ions in water. RSC Adv 5(14):10412-10417 
21. Zhang F, Zhang CL, Liang SONG, Zeng RC, Liu ZG, Cui HZ (2015) Corrosion of in situ grown MgAl-LDH coating on aluminum alloy. Trans Nonferrous Met Soc China 25(10):3498-3504

22. Ardau C, Frau F, Lattanzi P (2013) New data on arsenic sorption properties of $\mathrm{Zn}-\mathrm{Al}$ sulphate layered double hydroxides: influence of competition with other anions. Appl Clay Sci 80:1-9

23. Lu Z, Yu Z, Dong J, Song M, Liu Y, Liu X et al (2018) Facile microwave synthesis of a Z-scheme imprinted $\mathrm{ZnFe}_{2} \mathrm{O}_{4} / \mathrm{Ag} / \mathrm{PEDOT}$ with the specific recognition ability towards improving photocatalytic activity and selectivity for tetracycline. Chem Eng J 337:228-241

24. Doušová $B$, Machovič $V$, Koloušek $D$, Kovanda F, Dorničák V (2003) Sorption of As (V) species from aqueous systems. Water Air Soil Pollut 149(1-4):251-267

25. Wu X, Tan X, Yang S, Wen T, Guo H, Wang X, Xu A (2013) Coexistence of adsorption and coagulation processes of both arsenate and NOM from contaminated groundwater by nanocrystallined Mg/Al layered double hydroxides. Water Res 47(12):4159-4168

26. Yu XY, Luo T, Jia Y, Xu RX, Gao C, Zhang YX et al (2012) Threedimensional hierarchical flower-like $\mathrm{Mg}$-Al-layered double hydroxides: highly efficient adsorbents for $\mathrm{As}(\mathrm{V})$ and $\mathrm{Cr}(\mathrm{VI})$ removal. Nanoscale 4(11):3466-3474
27. Kitis M, Karakaya E, Yigit NO, Civelekoglu G, Akcil A (2005) Heterogeneous catalytic degradation of cyanide using copper-impregnated pumice and hydrogen peroxide. Water Res 39(8):1652-1662

28. Xiong YY, Li JQ, Le Gong L, Feng XF, Meng LN, Zhang $L$ et al (2017) Using MOF-74 for Hg2 + removal from ultra-low concentration aqueous solution. J Solid State Chem 246:16-22

29. Li L, Ma W, Shen S, Huang H, Bai Y, Liu H (2016) A combined experimental and theoretical study on the extraction of uranium by amino-derived metal-organic frameworks through post-synthetic strategy. ACS Appl Mater Interfaces 8(45):31032-31041

30. Bagherifam S, Komarneni S, Lakzian A, Fotovat A, Khorasani $\mathrm{R}$, Huang W et al (2014) Evaluation of $\mathrm{Zn}-\mathrm{Al}-\mathrm{SO}_{4}$ layered double hydroxide for the removal of arsenite and arsenate from a simulated soil solution: isotherms and kinetics. Appl Clay Sci 95:119-125

Publisher's Note Springer Nature remains neutral with regard to jurisdictional claims in published maps and institutional affiliations. 